\title{
Deposition of metallic glass coatings by electrospark processing in the medium of granules of Fe39Ni8Cr7W7Mo7Co2C16B14 composition
}

\author{
A. A. Burkov ${ }^{\dagger}$ \\ †burkovalex@mail.ru
}

Institute of Materials of Far Eastern Branch of RAS, 153 Tikhookeanskaya st., 680042, Khabarovsk, Russia

\begin{abstract}
The article is devoted to the deposition of FeNiCrWMoCoCB coatings on the basis of metallic glasses on a steel 35 substrate by an electrospark treatment in a medium of granules of pure metals and alloys used as electrode materials. X-ray diffraction studies have shown the predominance of the amorphous phase in the coating composition. It is shown that its fraction increases with an increase in the run-in time of the granules mixture used up to $300 \mathrm{~min}$. According to the X-ray data, during annealing, the amorphous phase persists up to the temperature of $600^{\circ} \mathrm{C}$ and then crystallizes into the phase of a complex iron-based carbide $(\mathrm{Cr}, \mathrm{Fe}, \mathrm{W}, \mathrm{Mo})_{23} \mathrm{Fe}_{12}(\mathrm{~W}, \mathrm{Mo})_{2} \mathrm{C}_{12}$. The corrosion properties, microhardness and wear resistance of the coatings obtained are studied. Polarization tests in a $3.5 \%$ aqueous $\mathrm{NaCl}$ solution showed an increase in the corrosion potential of the coatings with an increase in the run-in time of the granules used. A completely metallic glass coating showed a lower corrosion current and a higher polarization resistance as compared to steel 35. The study of oxidation kinetics has shown that the use of the FeNiCrWMoCoCB coating on steel 35 increases the resistance of its surface to high-temperature gas corrosion by 16 times in 100 hours of testing at a temperature of $700^{\circ} \mathrm{C}$. The microhardness of the deposited layers was about $8 \mathrm{GPa}$ that is 4 times higher than that of non-coated steel 35. The wear resistance of the deposited FeNiCrWMoCoCB coatings to dry sliding friction relative to P6M5 steel showed that its wear for $30 \mathrm{~km}$ of the test was almost 2 times lower than that of steel 35 . The proposed approach opens the possibility for a one-stage synthesis of metallic glasses in the form of coatings in an automatic mode from individual crystalline components.
\end{abstract}

Keywords: Fe-based metallic glasses, coatings, electrospark granules deposition, corrosion.

\section{Осаждение покрытий из металлического стекла электроискровой обработкой в среде гранул состава Fe39Ni8Cr7W7Mo7Co2C16B14}

\author{
Бурков А. А. ${ }^{\dagger}$ \\ Институт материаловедения Хабаровского НЦ ДВО РАН, ул. Тихоокеанская 153, 680042, Хабаровск, Россия
}

Статья посвящена осаждению FeNiCrWMoCoCB покрытий на основе металлических стекол на подложку из стали 35 электроискровой обработкой в среде гранул из металлов и сплавов, используемых в качестве электродных материалов. Исследования рентгеновской дифрактографии показали преобладание аморфной фазы в составе покрытий. Показано, что ее доля увеличивается с ростом времени приработки используемой смеси гранул до 300 мин. По данным рентгенофазового анализа аморфная фаза сохраняется до температуры $600^{\circ} \mathrm{C}$, а затем кристаллизуется в фазу сложного карбида на основе железа $(\mathrm{Cr}, \mathrm{Fe}, \mathrm{W}, \mathrm{Mo})_{23} \mathrm{Fe}_{12}(\mathrm{~W}, \mathrm{Mo})_{2} \mathrm{C}_{12}$. Изучены коррозионные свойства, микротвердость и износостойкость полученных покрытий. Поляризационные испытания в 3,5\% растворе $\mathrm{NaCl}$ показали снижение потенциала коррозии покрытий с ростом времени приработки гранул. Полностью аморфное покрытие показало более низкий ток коррозии и более высокое сопротивление поляризации по сравнению со сталью 35. Изучение жаростойкости показало, что применение FeNiCrWMoCoCB покрытия на стали 35 повышает стойкость ее поверхности к высокотемпературной газовой коррозии в 16 раз за 100 часов испытаний при температуре $700^{\circ} \mathrm{C}$. Микротвердость осажденных слоев составила около 8 Гпа, что в 4 раза выше, чем у непокрытой стали 35. Испытания стойкости осажденных FeNiCrWMoCoCB покрытий к сухому трению скольжения относительно стали Р6M5, показали, что его износ за 30 км испытаний был почти в 2 раза ниже, чем у стали 35. Предлагаемый подход открывает возможности для одностадийного синтеза металлических стекол в виде покрытий и в автоматическом режиме из индивидуальных кристаллических компонентов.

Ключевые слова: металлические стекла на основе железа, покрытия, электроискровая обработка в гранулах, коррозия. 


\section{1. Введение}

Аморфные металлические сплавы, также известные как металлические стекла (МС), представляют собой особый вид материала без кристаллической структуры. МС имеют множество применений из-за широкого спектра уникальных свойств. Так МС устойчивы к радиации [1], обладает антисептической эффективностью из-за наличия $\mathrm{Cu}$ или $\mathrm{Ag}$ в их составе, каталитической активностью из-за содержания благородных металлов, а также без них [2], отличной биосовместимостью [3] и т.д. МС на основе железа особенно привлекательны из-за высокой твердости, превосходной устойчивости к коррозии, хорошей износостойкости, отличных магнитно-мягких свойств и низкой стоимости. В связи с активным нуль-валентным железом (Fe0) такие MC могут быть использованы в качестве химических катализаторов для очистки сточных вод от биологически не разлагаемых загрязнителей, таких как бензол, хлорированные растворители, фенол, пестициды и толуол [2]. Для создания аморфного состояния в МС на основе железа необходимо достичь скоростей охлаждения материала порядка $10^{3}-10^{4} \mathrm{~K} / \mathrm{c}$ [4]. Скорости охлаждения материала в зоне воздействия низковольтных электрических разрядов (ЭР) между металлическими электродами достигают порядка $10^{5}-10^{7} \mathrm{~K} / \mathrm{c}[5]$. На явлении электрической эрозии материала под действием ЭР, основана технология нанесения покрытий, именуемая электроискровым легированием (ЭИЛ). В условиях многократного воздействия ЭР материал анода переносится на катод и образует покрытие. Благодаря конвективному перемешиванию катодного и анодного материала в процессе ЭИЛ, такие покрытия обладают высокой адгезией к металлической подложке. В работах [6, 7], эффект высоких скоростей охлаждения материала при ЭИЛ был использован для создания аморфных покрытий при использовании кристаллических электродов. Ранее, для автоматизации процесса ЭИЛ, нами была предложена схема нанесения покрытий в гранулах, которые выполняют функцию рабочего электрода (анода) из осаждаемого материала $[8,9]$. Такая схема обеспечивает многоточечный контакт дисперсного материала со всеми сторонами подложки, и поэтому разряды развиваются равномерно по всей поверхности обрабатываемой детали. Замена металлического стержня на крупные частицы не меняет физической сущности процессов при электроискровом воздействии, и поэтому модифицированный поверхностный слой на катоде формируется по аналогичному механизму «плавление-перенос-перемешивание-кристаллизация».

Данная работа посвящена изучению возможности синтеза покрытий из металлических стекол на подложке из стали 35 в процессе электроискрового осаждения в смеси гранул $\mathrm{Fe}_{39} \mathrm{Ni}_{8} \mathrm{Cr}_{7} \mathrm{~W}_{7} \mathrm{Mo}_{7} \mathrm{Co}_{2} \mathrm{C}_{16} \mathrm{~B}_{14}$, состоящей из кристаллических материалов отдельных компонентов и сплавов, а также исследованию коррозионного поведения и износостойкости полученных покрытий.

\section{2. Методика и материалы}

Была приготовлена смесь гранул, соответствующая составу $\mathrm{Fe}_{39} \mathrm{Ni}_{8} \mathrm{Cr}_{7} \mathrm{~W}_{7} \mathrm{Mo}_{7} \mathrm{Co}_{2} \mathrm{C}_{16} \mathrm{~B}_{14}$ (табл. 1). Сплавы $\mathrm{Cr}_{3} \mathrm{C}_{2}+50 \% \mathrm{Fe}$, WC $+8 \% \mathrm{Co}$ и $\mathrm{B}_{4} \mathrm{C}+80 \% \mathrm{Fe}$ были приготовлены методом порошковой металлургии из химически чистых порошков карбонильного железа и карбидов хрома, вольфрама и бора. Гранулы из приготовленных сплавов, а также молибдена, никеля и армко-железа нарезались в форме кубиков с ребром $4 \pm 1$ мм. Схема установки для осаждения покрытий в гранулах изображена на рис. 1. Подложка (1) из стали 35 , в форме цилиндра диаметром 12 мм и высотой 10 мм, помещалась в металлический контейнер (2) высотой 45 мм, диаметром 45 мм, заполненный гранулами (3). Контейнер устанавливался под углом $45^{\circ}$ и подсоединялся к двигателю (4). Частота вращения контейнера с гранулами составляла 60 об/мин. Образец, на который осаждалось покрытие, закреплялся на стальной стержень, подключенный к отрицательному выводу генератора импульсов (5) и подсоединялся к двигателю (6), вращающему катод в противоположную контейнеру сторону с частотой 30 об/мин. Положительный вывод генератора присоединялся к контейнеру. Генератор разрядных импульсов IMES-40 вырабатывал импульсы тока прямоугольной формы амплитудой $110 \mathrm{~A}$, длительностью 100 мкс

Табл. 1. Состав смеси гранул и их свойства.

Table 1. Composition of a granules mixture and their properties.

\begin{tabular}{|c|c|c|c|c|}
\hline \multicolumn{2}{|c|}{$\begin{array}{c}\text { Состав, } \\
\text { вес.\% } \\
\begin{array}{c}\text { Composition, } \\
\% \mathrm{wt}\end{array}\end{array}$} & $\begin{array}{c}\text { Температура } \\
\text { спекания, } \\
{ }^{\circ} \mathrm{C} \\
\text { Sintering } \\
\text { temperature, } \\
{ }^{\circ} \mathrm{C}\end{array}$ & $\begin{array}{c}\text { Прочность } \\
\text { на изгиб, } \\
\text { МПа } \\
\text { Strength, } \\
\mathrm{MPa}\end{array}$ & $\begin{array}{c}\text { Плотность, } \\
\text { г/см }{ }^{3} \\
\text { Density, } \\
\mathrm{g} / \mathrm{cm}^{3}\end{array}$ \\
\hline $\mathrm{Cr}_{3} \mathrm{C}_{2}+50 \% \mathrm{Fe}$ & 15.9 & 1350 & 140 & 6.7 \\
\hline $\mathrm{B}_{4} \mathrm{C}+80 \% \mathrm{Fe}$ & 18.2 & 1450 & 45 & 6.1 \\
\hline $\mathrm{WC}+8 \% \mathrm{Co}$ & 28.2 & 1450 & 1400 & 14.8 \\
\hline $\mathrm{Mo}$ & 12.9 & - & - & 10,2 \\
\hline $\mathrm{Fe}$ & 15.5 & 1350 & - & 7,2 \\
\hline $\mathrm{Ni}$ & 9.2 & 1350 & - & 7.9 \\
\hline
\end{tabular}

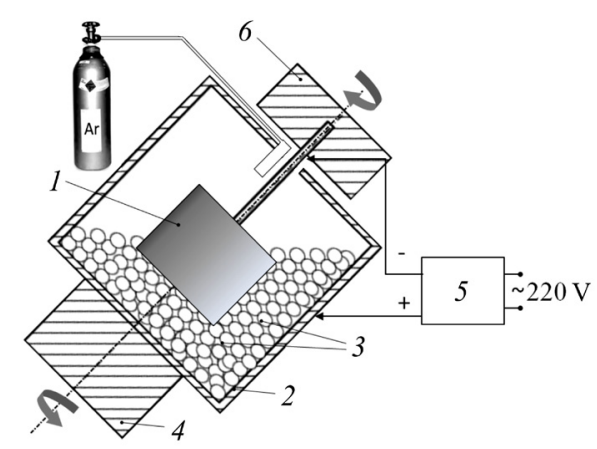

Рис. 1. Схема установки для электроискровой обработки в среде гранул.

Fig. 1. Scheme of the apparatus for electrospark granules deposition. 
и частотой 1000 Гц при напряжении 30 В. Для предотвращения окислительных процессов в рабочий объем контейнера подавался защитный газ - аргон со скоростью 7 л/мин. Для достижения равновесия осуществлялась электроискровая обработка смеси гранул с незаменяемым катодом т.н. “приработка”. В течение всех экспериментов гранулы не заменялись и не очищались. Каждые 30-90 минут погружался чистый катод и обрабатывался в течение 10 минут, а затем подвергался рентгенофазовому анализу для определения времени наступления равновесия. Покрытия, полученные при различном времени электроискровой приработки гранул, в дальнейшем будут обозначаться соответственно $1.5 \mathrm{~h}, 3 \mathrm{~h}, 4 \mathrm{~h}, 5 \mathrm{~h}, 5.5 \mathrm{~h}$.

Структура покрытий исследовалась с применением рентгеновского дифрактометра ДРОН-7 в $\mathrm{Cu}-\mathrm{K} \alpha$ излучении. Поляризационные испытания проводились в трехэлектродной ячейке после 20 мин погружения. Контр-электрод представлял собой платиновую проволоку, а электродом сравнения выступал стандартный хлорсеребряный электрод. Испытание на коррозионную стойкость проводили в 3,5\%-ном растворе $\mathrm{NaCl}$, с использованием потенциостата 8P-nano со скоростью сканирования $50 \mathrm{mB} / \mathrm{c}$. Потенциал коррозии, а также плотность тока коррозии были извлечены с участков методом экстраполяции Тафеля. Коррозионные характеристики были установлены с использованием соответствующего программного обеспечения.

Испытания на жаростойкость проводили в печи при $700^{\circ} \mathrm{C}$ на воздухе. Общее время тестирования составляло 100 часов. Образцы выдерживали при заданной температуре в течение 6 ч, затем удаляли и охлаждали на воздухе до комнатной температуры. Во время испытания на окисление образцы помещались в корундовый тигель, чтобы отслоившиеся оксиды собирались, и их масса учитывалась. Изменение массы образцов измеряли с использованием лабораторных весов с чувствительностью $10^{-4}$ г. Для исследования фазовых превращений при нагреве образцы последовательно отжигались в вакуумной печи Carbolite STF при температурах $500,600,700,800$ и $900^{\circ} \mathrm{C}$ в течение 1 часа при давлении 1,3 Па. Износостойкость покрытий согласно стандарту ASTM G99-04 исследовалась при сухом трении скольжения с применением контртел в виде дисков из быстрорежущей стали Р6M5 на скорости 12 м/с при нагрузке $25 \mathrm{H}$ на дистанции 30 км.

\section{3. Результаты}

\section{1. Структура покрытий}

При ЭИЛ происходит электрическая эрозия электродов, сопровождаемая взаимным обменом материала электродов с преимущественным полярным переносом анодного материала на поверхность катода в процессе протекания электрических разрядов [10]. Благодаря взаимному обмену материалом между гранулами разного состава и подложкой, а также его перемешиванию в ходе протекания многократных ЭР происходит выравнивание состава поверхности всех гранул и по- верхности катода до момента наступления равновесия [9]. Рис. 2 показывает изменение фазового состава поверхности подложки в зависимости от времени приработки. Согласно ему после 300 минут приработки на рентгеновских дифрактограммах не наблюдались острые Брэгговские рефлексы, что свидетельствовало о формировании аморфной структуры. По данным рентгенофазового анализа при отжиге аморфная фаза сохраняется до температуры $600^{\circ} \mathrm{C}$, а затем кристаллизуется в фазу сложного карбида на основе железа (Cr,Fe,W,Mo $)_{23} \mathrm{Fe}_{12}(\mathrm{~W}, \mathrm{Mo})_{2} \mathrm{C}_{12}$ [11] (рис. 3).

Кинетическая кривая осаждения покрытия $5.5 \mathrm{~h}$ на рис. 4 показывает, что с ростом времени обработки масса подложки увеличивалась с постепенным замедлением скорости привеса, аналогично традиционному ЭИЛ [10]. Так за 6 минут обработки на катоде накапливается 94\% от максимальной массы (рис. 4). Таким образом, показано, что время полной приработки смеси гранул состава $\mathrm{Fe}_{39} \mathrm{Ni}_{8} \mathrm{Cr}_{7} \mathrm{~W}_{7} \mathrm{Mo}_{7} \mathrm{Co}_{2} \mathrm{C}_{16} \mathrm{~B}_{14}$ составляло 300 минут или $\sim 2,6 \cdot 10^{5}$ импульсов $\cdot \mathrm{cm}^{-4}$ поверхности гранул, после чего они были готовы для нанесения покрытий с неизменным составом (рис. 2).

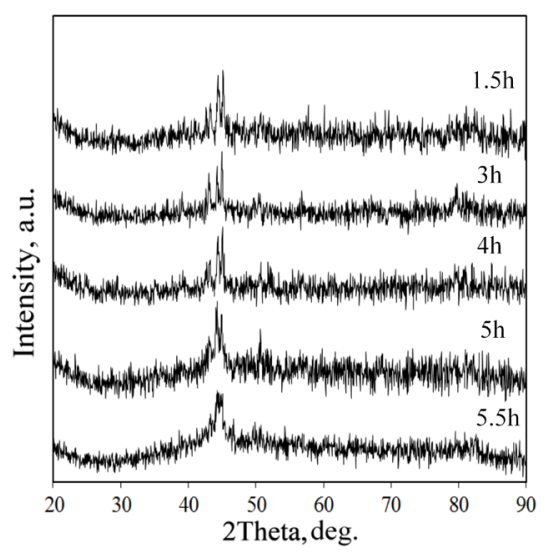

Рис. 2. Рентгеновские дифрактограммы FeNiCrWMoCoCB покрытий на стали 35 при различном времени электроискровой приработки гранул.

Fig. 2. X-ray diffraction patterns of FeNiCrWMoCoCB coatings on steel 35 for various time of electrospark procession of the granules.

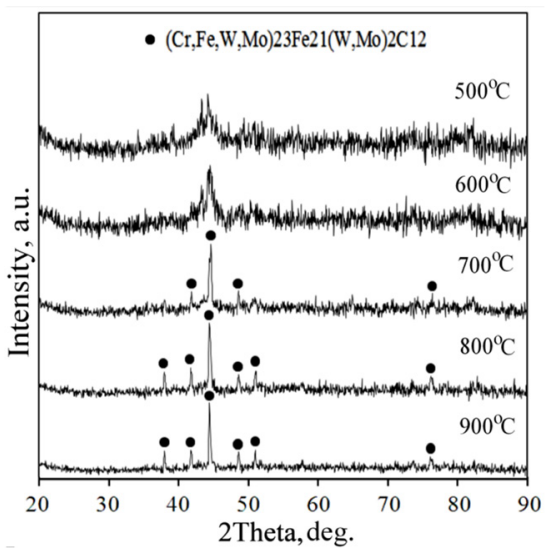

Рис. 3. Рентгеновские дифрактограммы покрытия $5.5 \mathrm{~h}$ на стали 35 при различных температурах отжига.

Fig. 3. X-ray diffraction patterns of the $5.5 \mathrm{~h}$ coating on steel 35 at different annealing temperatures. 


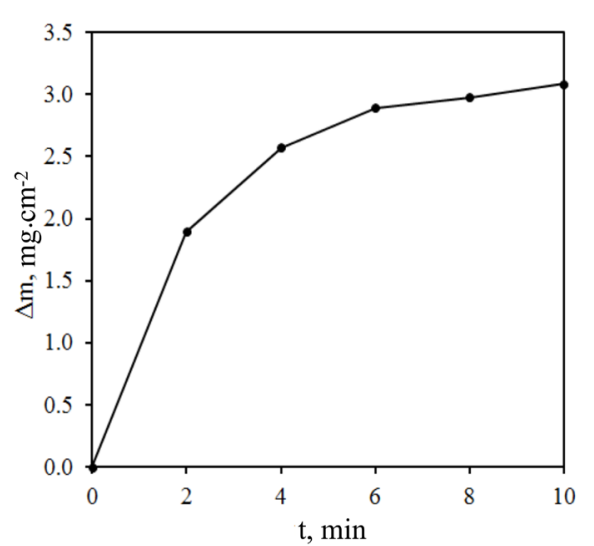

Рис. 4. Изменение массы катода в процессе электроискровой обработки в среде гранул состава $\mathrm{Fe}_{39} \mathrm{Ni}_{8} \mathrm{Cr}_{7} \mathrm{~W}_{7} \mathrm{Mo}_{7} \mathrm{Co}_{2} \mathrm{C}_{16} \mathrm{~B}_{14}$.

Fig. 4. Cathode mass gain in the process of electrospark granules deposition of the $\mathrm{Fe}_{39} \mathrm{Ni}_{8} \mathrm{Cr}_{7} \mathrm{~W}_{7} \mathrm{Mo}_{7} \mathrm{Co}_{2} \mathrm{C}_{16} \mathrm{~B}_{14}$ composition.

\section{2. Коррозионнье свойства}

На рис. 5 показаны потенциодинамические поляризационные кривые покрытий, полученных в гранулах с различным временем электроискровой приработки и стали 35 в 3,5\% растворе $\mathrm{NaCl}$ при комнатной температуре. На основе этих данных были вычислены ток коррозии $I_{\text {corr }}$, потенциал коррозии $E_{\text {corr }}$ и сопротивление поляризации $R_{p}$ (табл. 2). Для расчета $R_{p}$ использовано упрощенное выражение:

$$
R_{p}=\frac{b_{a} \cdot b_{c}}{2.303 I_{\text {corr }}\left(b_{a}+b_{c}\right)},
$$

где $b_{a}$ и $b_{c}$ это наклоны тафелевского участка анодной и катодной кривой, соответственно. Из табл. 2 следует, что потенциал коррозии подложки из стали 35 является самым отрицательным по сравнению с осажденными покрытиями. Потенциал коррозии формируемых покрытий снижался с ростом времени приработки гранул. Следует отметить, что ток коррозии у покрытий с недостаточной приработкой гранул (менее 5 часов) был выше, чем у стали 35. Это объясняется большей шероховатостью сформированных слоев порядка $R_{a}=6-8$ мкм, и соответственно, большей площадью границы раздела фаз металл - электролит, чем у стали 35. Тем не менее, ток коррозии покрытия 5h был ниже, а сопротивление поляризации было выше, чем у исходной стали (табл. 2). Поскольку сопротивление поляризации обратно пропорционально скорости коррозии, то можно заключить, что с ростом времени приработки гранул улучшаются антикоррозионные свойства FeNiCrWMoCoCB покрытий вследствие повышения их аморфности.

Опыты по определению жаростойкости стали 35 и электроискрового $\mathrm{FeNiCrWMoCoCB} \mathrm{покрытия} \mathrm{5.5h}$ показали, что при продолжительном изотермическом нагреве при $\mathrm{T}=700^{\circ} \mathrm{C}$ на воздухе наблюдается непрерывное увеличение массы испытуемых образцов (рис. 6а). Причиной такого приращения массы является захват кислорода поверхностью образцов с образованием оксида железа $\mathrm{Fe}_{2} \mathrm{O}_{3}$ в модификации гематита. Линии его спектра хорошо различимы на рентгеновских дифрак- тограммах, полученных после испытания на жаростойкость (вставка к рис. 6а). Поскольку оксидный слой покрывал покрытие 5.5h лишь фрагментами то на дифрактограмме заметны следы аморфного гало. Примечательно, что гематит на поверхности стали был сильно текстурирован в направлении 300 (вставка к рис. 6а) Сталь 35 окислялась линейно, а образец 5.5h наращивал массу по параболическому закону [12, 13]. Соответственно, скорость окисления образца с покрытием все время снижалась до величины $4,4 \cdot 10^{-6} \mathrm{M \Gamma} \cdot \mathrm{cm}^{-2} \mathrm{c}^{-1}$ после 100 часов высокотемпературной экспозиции, тогда как сталь 35 окислялась с постоянной скоростью около $6,6 \cdot 10^{-5} \mathrm{Mг} \cdot \mathrm{cm}^{-2} \mathrm{c}^{-1}$, что в 15 раз выше. Такое различие в характере окисления вызвано ростом толщины оксидной пленки на образце $5.5 \mathrm{~h}$ по мере экспозиции, за счет ее большей стойкости к циклическим термомеханическим нагрузкам нагрева-охлаждения. Под действием аналогичных нагрузок оксидная пленка на стали 35 постоянно отслаивалась при каждом цикле и нисколько не препятствовала контакту кислорода с железом. Всего за 100 часов испытаний образец с покрытием прибавил в массе в 16 раз меньше чем сталь 35 .

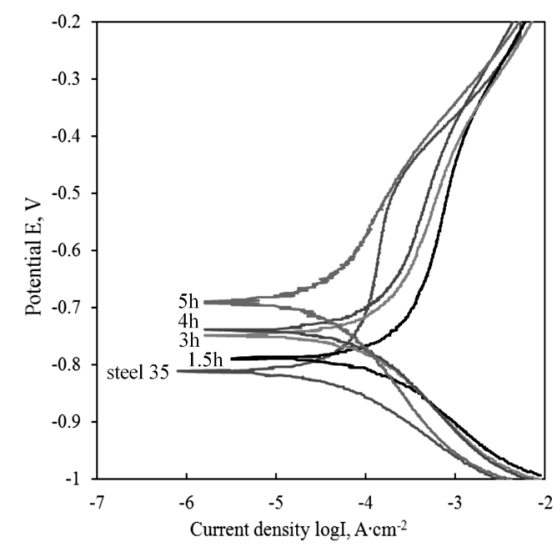

Рис. 5. Тафелевские поляризационные кривые стали 35 и аморфных покрытий, в 3,5\% растворе $\mathrm{NaCl}$.

Fig. 5. Tafel polarization curves of steel 35 and amorphous coatings, in $3.5 \% \mathrm{NaCl}$ solution.

Табл. 2. Коррозионные характеристики FeNiCrWMoCoCB покрытий и стали 35.

Table 2. Corrosion characteristics of FeNiCrWMoCoCB coatings and steel 35 .

\begin{tabular}{|c|c|c|c|}
\hline \multirow{2}{*}{$\begin{array}{c}\text { Oбразцы } \\
\text { Specimens }\end{array}$} & \multicolumn{3}{|c|}{$\begin{array}{c}\text { Параметры } \\
\text { Parameters }\end{array}$} \\
\cline { 2 - 4 } & $\begin{array}{c}E_{\text {corr }}, \mathrm{V} \\
\text { vs.Ag/AgCl }\end{array}$ & $I_{\text {corr }}, \mu \mathrm{A} \cdot \mathrm{cm}^{-2}$ & $R_{p}, \Omega \cdot \mathrm{cm}^{-2}$ \\
\hline Steel 35 & -0.78 & 43.1 & 390.9 \\
\hline $1.5 \mathrm{~h}$ & -0.768 & 112.11 & 166.9 \\
\hline $3 \mathrm{~h}$ & -0.72 & 89.9 & 185.4 \\
\hline $4 \mathrm{~h}$ & -0.72 & 54.7 & 283.8 \\
\hline $5 \mathrm{~h}$ & -0.66 & 29.9 & 458.4 \\
\hline
\end{tabular}




\section{3. Механические свойства}

Микротвердость покрытий из FeNiCrWMoCoCB металлических стекол, полученных при различном времени приработки, находилась в диапазоне 7,3-8,5 ГПа, что в 3,5-4 раза выше, чем у непокрытой стали 35 (табл. 3). Из табл. 3 следует, что микротвердость на поверхности покрытий возрастала в первые моменты времени приработки от 1,5 до 3 часов, а затем к 5 часам приработки достигла равновесия, о чем свидетельствует снижение значений доверительных интервалов. Высокий разброс значений при измерении микротвердости у образцов $1.5 \mathrm{~h}-4 \mathrm{~h}$ вызван гетерогенностью состава их поверхности из-за неполного выравнивания составов поверхности гранул.

Рис. 7 показывает, что образцы, $3 \mathrm{~h}$ и $4 \mathrm{~h}$ изнашивались примерно одинаково, при этом, их износ за все время испытаний был на $~ 10 \%$ выше, чем у стали 35 , что можно объяснить более высокой шероховатостью их поверхности. Наименьшему изнашиванию подверглись покрытия $5 \mathrm{~h}$ и 5.5h часов приработки, причем кривые их износа имели одинаковый характер (рис. 7). Износ данных покрытий за 30 км пути трения был в 1,8 раза меньше, чем у стали 35 (рис. 7а). Характерно, что скорость износа всех покрытий, за исключением $1.5 \mathrm{~h}$, снижалась
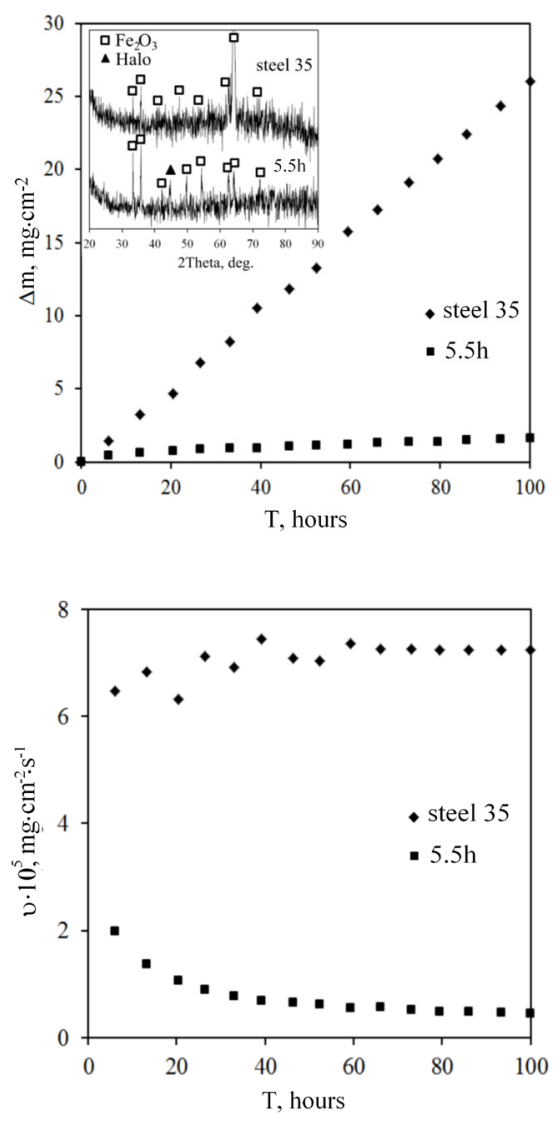

b

Pис. 6. Жаростойкость (а) и скорость коррозии (b) покрытия $5.5 \mathrm{~h}$, по сравнению со сталью 35 при температуре $700^{\circ} \mathrm{C}$ на воздухе.

Fig. 6. Corrosion resistance (a) and corrosion rate (b) of 5.5h coating, compared to steel 35 at $700^{\circ} \mathrm{C}$ in air. за все во время испытаний, тогда как у стали 35 скорость износа была постоянной (рис. 7b). Таким образом, можно заключить, что повышение времени приработки гранул до 5 часов улучшает трибологические свойства покрытий, однако дальнейшая приработка не приносит эффекта, что объясняется выравниванием состава всех электродов и формированием аморфной структуры, что согласуется с данными рис. 2.

Табл. 3. Микротвердость осажденных покрытий с применением смеси гранул различной приработки.

Table 3. Microhardness of the deposited coatings obtained by using a granules mixture of different run-in compared to steel 35 .

\begin{tabular}{|c|c|c|c|c|c|c|}
\hline \multirow{2}{*}{$\begin{array}{c}\text { Параметр } \\
\text { Parameter }\end{array}$} & \multicolumn{5}{|c|}{$\begin{array}{c}\text { Образцы } \\
\text { Specimens }\end{array}$} \\
\cline { 2 - 7 } $\begin{array}{c}\text { Средняя } \\
\text { микротвердость, ГПа } \\
\text { Average } \\
\text { microhardness, GPa }\end{array}$ & 2.1 & 7.3 & 8.2 & 8.5 & 8.0 & 8.4 \\
\hline $\begin{array}{c}\text { Стандартное } \\
\text { отклонение, ГПа } \\
\begin{array}{c}\text { Standard } \\
\text { deviation, GPa }\end{array}\end{array}$ & 0.2 & 2.1 & 2.0 & 2.2 & 1.4 & 1.4 \\
\hline
\end{tabular}

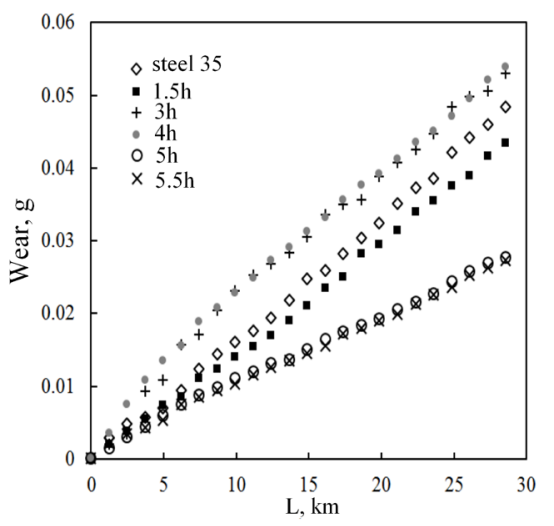

a

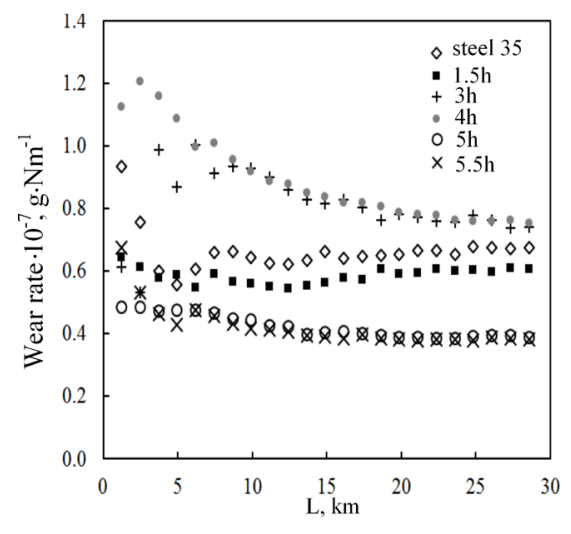

$b$

Pис. 7. Износ (a) и скорость износа (b) покрытий на основе $\mathrm{FeNiCrWMoCoCB} \mathrm{полученных} \mathrm{с} \mathrm{помощью} \mathrm{гранул} \mathrm{различной}$ степени приработки, по сравнению со сталью 35.

Fig. 7. Wear (a) and wear rate (b) of FeNiCrWMoCoCB coatings obtained by using a granules mixture of different run-in compared to steel 35 . 
В целом электроискровое осаждение покрытий на основе FeNiCrWMoCoCB металлических стекол в среде гранул позволяет получать слои, которые близки по скорости износа к традиционным ЭИЛ покрытиям из металлических стекол на стали 35 [14]. Однако они значительно уступают по износостойкости электроискровым покрытиям на основе твердых сплавов которые снижают скорость износа стали 35 в 10 раз, что обусловлено умеренной твердостью металлических стекол около 8 ГПа (табл. 3), относительно покрытий из WC-Сo сплавов ( $\geq 12$ ГПа) $[15,16]$, а также повышенной хрупкостью.

\section{Заключение}

По результатам работы показана возможность синтеза FeNiCrWMoCoCB аморфных металлических покрытий электроискровой обработкой в среде гранул разнородного состава. Полученные покрытия обладали высокими антикоррозионными свойствами при умеренной твердости и износостойкости, что вполне характерно для металлических стекол на основе железа. Аморфные $\mathrm{FeNiCrWMoCoCB} \mathrm{покрытия} \mathrm{могут} \mathrm{быть} \mathrm{использованы}$ для защиты стальных изделий от коррозии при эксплуатации в условиях повышенных температур, а также, в качестве катализаторов для очистки промышленных сточных вод на носителе из дешевой стали. Демонстрируемое упрочнение стали $35 \mathrm{FeNiCrWMoCoCB}$ аморфными металлическими покрытиями является дополнительным преимуществом данного подхода.

Благодарность/Acknowledgements. Работа выполнена при поддержке правительства Хабаровского края в борме субсидии из краевого бюджета на реализацию проектов в 2017 году в области фундаментальных и технических наук. Автор выражает признательность Зайковой Е. Р. за помощь в измерении микротвердости.

\section{Литература/References}

1. H. Zhang, X. Mei, X. Zhang, X. Li, Y. Wang, J. Sun., Y. Wang. Nucl. Instrum. Methods Phys. Res., Sect. B. 375, 79- 86 (2016). doi: 10.1016/j.nimb.2016.03.015

2. Z. Deng, X.H. Zhang, K.C. Chan, L. Liu,
T.Li. Chemosphere, 174, $76-81$ (2017). doi: 10.1016/j. chemosphere.2017.01.094

3. S. Li, Q. Wei, Q. Li, B. Jiang, Y. Chen, Y. Sun. Mater. Sci. Eng. 52, 235 - 241 (2015). doi: 10.1016/j.msec.2015.03.041

4. L. Liu, C. Zhang. Thin Solid Films. 561, $70-86$ (2014). doi: 10.1016/j.tsf.2013.08.029

5. Q.H.Li, T.M.Yue,Z.N.Guo,X.Lin.Metall.Mater.Trans.A. 44A, 1767 - 1778 (2013). doi: 10.1007/s11661-012-1535-4

6. M. Fakoori, M.F. Hasanabadi, F.M. Ghaini, M. Ebrahimnia, H. R. Shahverdi Surf. coat. technol. 270, 95 - 101 (2015). doi: 10.1016/j.surfcoat.2015.03.016

7. A. A. Burkov, S. A. Pyachin, A. V.Zaytsev, E. A. Kirichenko, M. A. Teslina, N. A. Syuy. Letters on materials, 2016, 6(3) 163 - 167 (2016). doi: 10.22226/2410-3535-2016-3-163-1 67

8. A.A. Burkov, S.A. Pyachin, L.P. Metlitskaya, M.A. Pugachevsky. Strengthening technologies and coatings. 5, 16-21, 2013. (in Russian) [А. А. Бурков, C.А. Пячин, Л.П. Метлицкая, М.А. Пугачевский. Упрочняющие технологии и покрытия. 5, 16-21, 2013.]

9. A. A. Burkov, S. A. Pyachin. Mater. and Des. 80, 109-115 (2015). doi: 10.1016/j.matdes.2015.05.008

10. B. R. Lazarenko, NI Lazarenko. Electrospark processing of current-conducting materials. Moscow: Publishing House of the Academy of Sciences USSR. 1958. 183 p. (in Russian) [Б.Р. Лазаренко, Н.И. Лазаренко. Электроискровая обработка токопроводящих материалов. М.: Изд-во АН СССР. 1958. 183 с.]

11. H.J. Goldschmidt, Interplanar spacings of carbides in steels, Metallurgia, 40, 103 - 104 (1949).

12. N. Birks, G.H. Meier, and F.S. Pettit, Introduction to the High-Temperature Oxidation of Metals, Cambridge University Press, Cambridge, 2006.

13. D. J. Young, High Temperature Oxidation and Corrosion of Metals, Elsevier Science S. A., London, 2008.

14. A. A. Burkov, S. A. Pyachin, M. A. Ermakov, A. V. Syuy. J. of Materi Eng and Perform. 26, $901-908$ (2017). doi: 10.1007/s11665-016-2493-6

15. A.A. Burkov. J. Frict. Wear. 37, 385-388 (2016). doi:10.3103/S1068366616040048

16. A.A. Burkov, S.A. Pyachin. Solid State Phenomena. 213, $131-136$ (2014). doi: 10.4028/www.scientific.net/ SSP. 213.131 